\title{
A comparative study of intrathecal clonidine VS dexmedetomidine in caesarean patients
}

\author{
Selvakumar Rajasekaran ${ }^{1, *}$, Suresh Murugaih ${ }^{2}$, Asha Anandan³ ${ }^{3}$, Ayshvarya Ramalingam ${ }^{4}$ \\ ${ }^{1}$ Professor \& HOD, ${ }^{2}$ Associate Professor, ${ }^{3,4}$ Senior Resident, Dept. of Anaesthesia, K.A.P. Viswanatham Government Medical \\ College, Tiruchirappalli, Tamil Nadu, India
}

*Corresponding Author:

Email: drsurela@yahoo.com

Received: $10^{\text {th }}$ August, 2016

Accepted: $21^{\text {st }}$ May, 2017

\begin{abstract}
Introduction: Spinal anaesthesia is the most commonly employed technique for Caesarean section. Many drugs such as opioids as intrathecal additives such have been widely studied found to be associated with respiratory depression, pruritis, etc. Upcoming studies on alpha-2 agonists as intrathecal additives have been found promising and will replace opioids soon. Knowledge on the efficacy of the individual a2 agonists over one another is lacking. So the aim of the study is to compare the spinal additive effect of dexmedetomidine and clonidine in pregnant patients for caesarean section.

Materials and Methods: Ninety patients belonging to ASA group I and II of age group of $20-40$ years were included in the study. Patients with PIH, Diabetes, Body weight above 100kg, Height less than $145 \mathrm{~cm}$, Post spinal surgeries, spinal deformity, and known history of Coagulopathy and allergic to study drugs, documented IUGR, intrauterine anomaly and patients those who are not willing for spinal anaesthesia were excluded from the study. They were randomly allocated into three groups of 30 patients each, Group D where the patients received dexmedetomidine $5 \mu \mathrm{g}$ with bupivacaine $10 \mathrm{mg}$, Group $\mathrm{C}$ where the patients received clonidine $15 \mu \mathrm{g}$ with bupivacaine $10 \mathrm{mg}$ and Group B where the patient received bupivacaine $10 \mathrm{mg}$ with $0.9 \%$ saline $0.5 \mathrm{ml}$. The duration of the sensory and the motor blockade, two segment regression times, duration of the postoperative analgesia, sedation and neonatal wellbeing with maternal hemodynamic changes were studied.

Results: Demographic characteristics and hemodynamic parameters were comparable between the three groups. The onset and maximal sensory block was faster in Dxm and clonidine groups $(162 \pm 41.40 ; 166 \pm 37.57)$ than control group (254.67 \pm 28.73$)$ which was statistically significant. The two segment regression time was significantly shorter in control group (67.53 \pm 5.94$)$ than Dxm and clonidine group $(103.47 \pm 8.08 ; 108 \pm 6.90)$. Dxm and clonidine group showed shorter time $(3.40 \pm 0.84 ; 3.13 \pm 0.50)$ to reach Bromage grade 3 motor block than control group (4.52 \pm 1.78$)$. The maximum sedation score recorded in both Dxm and clonidine group was 2.The time of onset (minutes) of sedation between Dxm and clonidine groups which was $(8.9 \pm 2.85 ; 7.43 \pm 2.27)$ were statistically insignificant.

Conclusion: Addition of intrathecal clonidine $15 \mu \mathrm{g} /$ dexmedetomidine $5 \mu \mathrm{g}$ to $10 \mathrm{mg}$ of bupivacaine in LSCS patients increase the duration of motor and sensory blockade, with little changes in maternal hemodynamics without any changes in neonatal outcome.
\end{abstract}

Keywords: Caesarean section, Clonidine, Dexmedetomidine, Spinal anaesthesia.

\section{Introduction}

Spinal anesthesia is the most commonly used technique for caesarean section as it is very economical and safe to administer. In spinal anesthesia, lignocaine and bupivacaine are commonly used which give good anesthesia and analgesia during intraoperative period but short lived analgesia in the postoperative period. ${ }^{1}$ In postoperative period adequate pain relief is important as ensures early mobilization and less incidence of urinary retention thus decreases the hospital stay. ${ }^{2}$ In order to prolong the analgesia during postoperative period, intrathecal additives like adrenaline, morphine, buprenorphine, ketamine, and fentanyl are used. ${ }^{3}$ Opioids are commonly used as spinal adjuncts to ensure good postoperative analgesia, but the complications associated with opioids usage such as respiratory depression are well known. ${ }^{4}$ The $\alpha 2$ agonists are gaining popularity in anesthesia as an adjunct in regional anesthesia, premedication in general anesthesia and in ICU sedation.
Clonidine is a partial $\alpha_{2}$ agonist used intrathecally with well established efficacy and safety. It prolongs the duration of motor and sensory spinal blockade when used along with local anesthetics. Dexmedetomidine(Dxm) is a highly selective another $\alpha_{2}$ adrenoreceptor agonist and has been approved by Food and Drug Administration (FDA) as an intravenous sedative and co analgesic drug. Its $\alpha 1 / \alpha 2$ selectivity is eight times higher than clonidine. ${ }^{5-6}$

So far the existing studies have compared either clonidine or dexmedetomidine with that of the opioids, but studies to compare the effect of these two $\alpha 2$ agonists as spinal additive are lacking. So we decided to compare the spinal additive effect of dexmedetomidine and clonidine in pregnant patients for caesarean section. We also used a control group with only bupivacaine.

\section{Materials and Methods}

After getting approval from institutional Ethical committee, 90 patients were selected randomly into three groups. Those aged between $20-40$ years, with ASA 
physical status of I-II, coming with singleton pregnancy scheduled for elective caesarean delivery were included in the study. Patient refusal, those with comorbidities such as PIH, Diabetes, belonging to ASA III, IV, with body weight $>100 \mathrm{~kg}$ and height $<145 \mathrm{~cm}$, with spinal deformities, coagulation abnormalities and history of allergy to the study drugs, and those patients with IUGR, intrauterine anomaly, PROM were excluded from the study.

Patients were assigned into three groups randomly by computer based random allocation numbers

Table 1: Drug solutions used in the three groups

\begin{tabular}{|c|l|l|}
\hline Groups & Volume & \multicolumn{1}{c|}{ Drugs } \\
\hline Group D & $2.5 \mathrm{ml}$ & $\begin{array}{l}\text { Dexmedetomidine } 5 \mu \mathrm{g}+\text { Normal Saline(NS) }(0.5 \mathrm{ml}) \\
+ \text { Bupivacaine 10mg }(2 \mathrm{ml})\end{array}$ \\
\hline Group C & $2.5 \mathrm{ml}$ & $\begin{array}{l}\text { Clonidine } 15 \mu \mathrm{g}+\mathrm{NS}(0.5 \mathrm{ml}) \\
+ \text { Bupivacaine 10mg }(2 \mathrm{ml})\end{array}$ \\
\hline Group B & $2.5 \mathrm{ml}$ & $\begin{array}{l}\text { NS }(0.5 \mathrm{ml}) \\
\text { Bupivacaine } 10 \mathrm{mg}(2 \mathrm{ml})\end{array}$ \\
\hline
\end{tabular}

The study drug solution was prepared by the second author who was not involved in the study. Both anesthetist and patient were blinded to the study drug.

In preoperative room area, all parturient were assessed with clinical history and examination and then baseline NIBP and pulse rate were recorded. No premedication was administered preoperatively. Preloading was done with lactated ringer's solution of $20 \mathrm{ml} / \mathrm{kg}$ started 15 minutes before the induction of spinal anaesthesia. Intraoperative standard anaesthesia monitoring consists of pulse rate, ECG, NIBP, SPO2. Under strict aseptic precaution, spinal anaesthesia was performed in right lateral position at L2-3/L3-4 level through midline approach. Spinal needle used was Quincke 23G/25G. Immediately after spinal injection patient was turned to supine position and $\mathrm{O} 2(4-6 \mathrm{~L} / \mathrm{min})$ was given through face mask.

The time of administration of spinal anaesthesia was taken as zero minute. The sensory block was tested by alcohol soaked cotton in midaxillary line bilaterally which was tested every 30 seconds till it reaches its maximum level. The motor blockade was assessed every minute by Modified Bromage scale. The time from intrathecal injection to two dermatome sensory regression, sensory regression to S2 dermatome and motor block regression to modified Bromage 0 was recorded

Table 2: Modified Bromage scale

\begin{tabular}{|c|l|}
\hline Bromage scale- 0 & Patient is able to move hip, knee, and ankle. \\
\hline Bromage scale- 1 & $\begin{array}{l}\text { Patient unable to move the hip but able to move the knee } \\
\text { and ankle. }\end{array}$ \\
\hline Bromage scale- 2 & $\begin{array}{l}\text { Patient is unable to move hip and knee but able to move } \\
\text { ankle. }\end{array}$ \\
\hline Bromage scale-3 & Patient is unable to move hip, knee and ankle. \\
\hline
\end{tabular}

Sedation score was assessed by Ramsay Sedation Score. The sedation score was assessed every 5 minutes during intraoperative period till reaches the maximum level. In postoperative period it was assessed in every 30 minutes till the patient was fully awake.

Table 3: Ramsay Sedation Score

\begin{tabular}{|l|l|}
\hline \multicolumn{2}{|l|}{ Ramsay Sedation Scale: } \\
\hline Grade 0 & Awake, conscious, no sedation, to slightly restless \\
\hline Grade 1 & Calm and compose \\
\hline Grade 2 & Awake on verbal command \\
\hline Grade 3 & Awake on gentle tactile stimulation \\
\hline Grade 4 & Awake on vigorous shaking \\
\hline Grade 5 & Unarousable \\
\hline
\end{tabular}

Postoperative pain was assessed by visual analog score using word scale. First analgesic requirement time is defined as from the time of spinal injection to the time at when the patient requires analgesia. The rescue analgesic used was inj.Tramadol 100mg i.m. 
Table 4: visual analog score

\begin{tabular}{|l|l|}
\hline score-0 & No pain \\
\hline Score $1-2$ & Least pain \\
\hline Score3-4 & Mild pain \\
\hline Score5-6 & Moderate pain \\
\hline Score $7-8$ & Severe pain \\
\hline Score $9-10$ & Excruciating pain \\
\hline
\end{tabular}

Preoperative hemodynamics was considered as base line values. Intraoperative hemodynamics was calculated from the time of spinal injection to shifting to the immediate recovery room. Post-operative parameters were recorded from immediate recovery room to first analgesic requirement period in the postoperative ward.

Intraoperative and post-operative complications like nausea, vomiting, pruritis, hypotension and respiratory depression were recorded. Hypotension is defined as $20 \%$ decrease in systolic blood pressure or systolic blood pressure of <100mmHg. Hypotension can be treated with left uterine tilt, increasing the fluid infusion and inj. Ephedrine 6mg i.e, bolus. Bradycardia is defined as the pulse rate of $<60 \mathrm{bpm}$, which can be treated with inj. Atropine 0.3-0.6mg IV. Respiratory depression ( $R R<8$ or spo2 $<95 \%$ ) can be treated with O2 supplementation.

The observed data were analyzed by SPSS version 21.0 software. Continuous variables were compared with one way ANOVA. The comparison was done with using chi-Square or Benforroni test as appropriate value reported at the $95 \%$ confidence interval. $\mathrm{P}$ value $<0.005$ was considered as statistically significant.

Sample size was calculated using priori power analysis. We did a pilot study in which the average difference in the duration of sensory blockade between dexmedetomidine and clonidine groups was 78 minutes with a standard deviation of 5.2. Using these variables and assuming a confidence level of $95 \%$ and power of 0.8 and alpha error of 0.2 , we calculated 26 patients for each groups and calculating for the dropouts and mishaps we arrived to use a sample size of 30 for each groups.

\section{Results}

Demographic data regarding age, weight and height was compared among the three groups. Base line mean pulse rate and MAP was similar in three groups. During Intraoperative period mean pulse rate recorded showed no significant difference among three groups. Three groups were showed reduction in pulse rate but more with Dexmedetomidine and clonidine group (82.75 \pm 8.09 $\& 87.18 \pm 14.86)$ than control group $(86.36 \pm 3.31)$. But postoperative mean pulse rate was significantly lower in both Dexmedetomidine and clonidine groups $(79.27 \pm 3.97 ; 78.33 \pm 3.95)$ than control group (86.45 \pm 0.94$)$. Mean BP changes during intraoperative period was insignificant among the three groups but the reduction more in dexmedetomidine and clonidine group $(80 \pm 6.05 \quad \& 78.32 \pm 5.88)$ than control group $(80.93 \pm 4.26)$. But in the postoperative period, MAP was significantly lower in dexmedetomidine and clonidine groups $(86.70 \pm 5.27 ; 81.14 \pm 3.79)$ when compared to control group (87.88 \pm 3.36 ). Both (dexmedetomidine) Dxm and clonidine produces fall in pulse rate and blood pressure but with clonidine the fall in pulse rate and blood pressure was slightly more than Dxm group. But both drugs did not produce any significant hypotension or bradycardia which warranted treatment.

The onset and maximal sensory block was faster in Dxm and clonidine groups $(162 \pm 41.40 ; 166 \pm 37.57)$ than control group $(254.67 \pm 28.73)$ which was statistically significant. But between Dxm and clonidine group it was statistically insignificant $(\mathrm{P}>0.05)$. The two segment regression time was significantly shorter in control group (67.53 \pm 5.94$)$ than Dxm and clonidine group $(103.47 \pm 8.08 ; 108 \pm 6.90)$. Clonidine group showed slightly longer time than Dxm group but statistically insignificant $(\mathrm{P}>0.05)$. Time to reach $\mathrm{S} 2$ level was estimated at the time taken for the return of full skin sensation which was significantly longer in Dxm and clonidine group $(304 \pm 22.53 ; 294.67 \pm 28.73)$ than the control group (214 \pm 17.14$)$. Dxm group shows clinically significant longer time than clonidine group but it was statistically insignificant $(\mathrm{P}>0.05)$. First analgesic requirement time was significantly prolonged in Dxm and clonidine group $(231 \pm 17.08 ; 316 \pm 16.93)$ than control group (102.23 \pm 7.40$)$. Clonidine group shows clinically longer time than Dxm group but it was statistically insignificant $(\mathrm{P}>0.05)$

All patients involved in the study achieved Bromage grade 3 motor blockade. However Dxm and clonidine group showed shorter time $(3.40 \pm 0.84 ; 3.13 \pm 0.50)$ to reach Bromage grade 3 motor block than control group (4.52 \pm 1.78$)$. Both Dxm and clonidine groups were almost similar in character in this regard. Motor recovery time was longer in Dxm and clonidine groups than control group.

The maximum sedation score recorded in both Dxm and clonidine group was 2.The time of onset (minutes) of sedation between Dxm and clonidine groups which was $(8.9 \pm 2.85 ; 7.43 \pm 2.27)$ were statistically insignificant $(\mathrm{P}>0.05)$. No sedation recorded in control group.

The neonatal assessment was recorded among the three groups as $1^{\text {st }}$ and $5^{\text {th }}$ minute Apgar score. There is no significant difference (Apgar> 7) among the study groups $(\mathrm{P}>0.05)$

Hypotension was mild to moderate among the three groups but it was less in Dxm and clonidine groups 7 (23\%); 8 (26.6\%) when compare to that of control group $(33 \%)$. No event of bradycardia was recorded in the groups. Nausea and vomiting were more in number in 
control group 6 (20\%) than study group $4(13 \%)$ each. No pruritis and dryness of mouth was recorded among the three groups.

Table 5: Patient demographic data

\begin{tabular}{|l|c|c|c|}
\hline \multicolumn{1}{|c|}{ Variables } & Dxm $(\mathbf{n}=\mathbf{3 0})$ & Clonidine $(\mathbf{n}=\mathbf{3 0})$ & Cont $(\mathbf{n}=\mathbf{3 0})$ \\
\hline Age(years) & $23.73 \pm 3.35$ & $24 \pm 1.43$ & $23.9 \pm 1.42$ \\
\hline Weight $(\mathrm{kg})$ & $57.7 \pm 1.82$ & $59.13 \pm 4.60$ & $57.97 \pm 5.44$ \\
\hline Height $(\mathrm{cm})$ & $154.6 \pm 4.09$ & $155.87 \pm 2.78$ & $153.9 \pm 2.72$ \\
\hline
\end{tabular}

Table 6: Characteristics of spinal block

\begin{tabular}{|l|c|c|c|c|c|}
\hline \multicolumn{1}{|c|}{ Observations } & $\begin{array}{c}\text { Dex } \\
\text { group(30) }\end{array}$ & $\begin{array}{c}\text { Clonidine } \\
\text { group(30) }\end{array}$ & $\begin{array}{c}\text { Cont } \\
\text { group(30) }\end{array}$ & F test & P value \\
\hline $\begin{array}{l}\text { Time to reach } \\
\text { maximum sensory } \\
\text { level/seconds (T4) }\end{array}$ & $162 \pm 41.40$ & $166 \pm 37.57$ & $254.67 \pm 28.73$ & 241.08 & 0.001 \\
\hline $\begin{array}{l}\text { Time to reach Grade } \\
3 \text { motor block/mins }\end{array}$ & $3.40 \pm 0.84$ & $3.13 \pm 0.50$ & $4.52 \pm 1.78$ & 105.33 & 0.000 \\
\hline $\begin{array}{l}\text { Two segment } \\
\text { regression } \\
\text { time/ mins }\end{array}$ & $103.47 \pm 8.08$ & $108 \pm 6.90$ & $67.53 \pm 5.94$ & 298.157 & 0.000 \\
\hline $\begin{array}{l}\text { Sensory recovery } \\
\text { time to S2/mins }\end{array}$ & $304 \pm 22.53$ & $294.67 \pm 28.73$ & $214 \pm 17.14$ & 135.462 & 0.000 \\
\hline $\begin{array}{l}\text { First analgesic } \\
\text { requirement } \\
\text { time/mins }\end{array}$ & $231 \pm 17.08$ & $316 \pm 16.93$ & $102.23 \pm 7.40$ & 1648.861 & 0.000 \\
\hline
\end{tabular}

Table 7: Ramsay Sedation Score

\begin{tabular}{|l|c|c|c|}
\hline & $\begin{array}{c}\text { Dxm } \\
\text { group(30) }\end{array}$ & $\begin{array}{c}\text { Clonidine } \\
\text { group(30) }\end{array}$ & P value \\
\hline Mean Onset Time & $8.9 \pm 2.85$ & $7.43 \pm 2.27$ & 0.27 \\
\hline
\end{tabular}

Table 8: Neonatal Assessment

\begin{tabular}{|l|c|c|c|c|c|}
\hline \multicolumn{1}{|c|}{ Apgar score } & $\begin{array}{c}\text { Dex } \\
\text { group(30) }\end{array}$ & $\begin{array}{c}\text { Clonidine } \\
\text { group(30) }\end{array}$ & $\begin{array}{c}\text { Cont } \\
\text { group }(30)\end{array}$ & F test & P value \\
\hline 1st min Apgar & $8.07 \pm 0.45$ & $7.93 \pm 0.45$ & $7.97 \pm 0.18$ & 6.013 & 0.104 \\
\hline 5th min Apgar & $9.27 \pm 0.45$ & $9.43 \pm 0.50$ & $9.13 \pm 0.35$ & 3.531 & 0.234 \\
\hline
\end{tabular}

Table 9: Adverse effects in studied groups

\begin{tabular}{|l|c|c|c|}
\hline \multicolumn{1}{|c|}{ Complications } & $\begin{array}{c}\text { Dxm } \\
\text { group(30)\% }\end{array}$ & $\begin{array}{c}\text { Clonidine } \\
\text { group(30) \% }\end{array}$ & $\begin{array}{c}\text { Cont } \\
\text { group }(30) \%\end{array}$ \\
\hline Hypotension & $7(23)$ & $8(26.6)$ & $10(33)$ \\
\hline Bradycardia & 0 & 0 & 0 \\
\hline Nausealvomiting & $4(13)$ & $4(13)$ & $6(20)$ \\
\hline Pruritis & 0 & 0 & 0 \\
\hline
\end{tabular}

Table 10: Hemodynamic Changes

\begin{tabular}{|l|c|c|c|c|c|}
\hline \multicolumn{1}{|c|}{ Mean Pulse /MAP } & $\begin{array}{c}\text { Dxm } \\
\text { group(30) }\end{array}$ & $\begin{array}{c}\text { Clonidine } \\
\text { group(30) }\end{array}$ & $\begin{array}{c}\text { Cont } \\
\text { group(30) }\end{array}$ & F test & P value \\
\hline Intraop pulse & $82.75 \pm 8.09$ & $87.18 \pm 14.86$ & $86.36 \pm 3.31$ & 0.449 & 0.644 \\
\hline Postop pulse & $79.27 \pm 3.97$ & $78.33 \pm 3.95$ & $86.45 \pm 0.94$ & 21.95 & 0.000 \\
\hline Intraop BP & $80 \pm 6.05$ & $78.32 \pm 5.88$ & $80.93 \pm 4.26$ & 0.471 & 0.631 \\
\hline Postop BP & $86.70 \pm 5.27$ & $81.14 \pm 3.79$ & $87.88 \pm 3.36$ & 8.195 & 0.001 \\
\hline
\end{tabular}




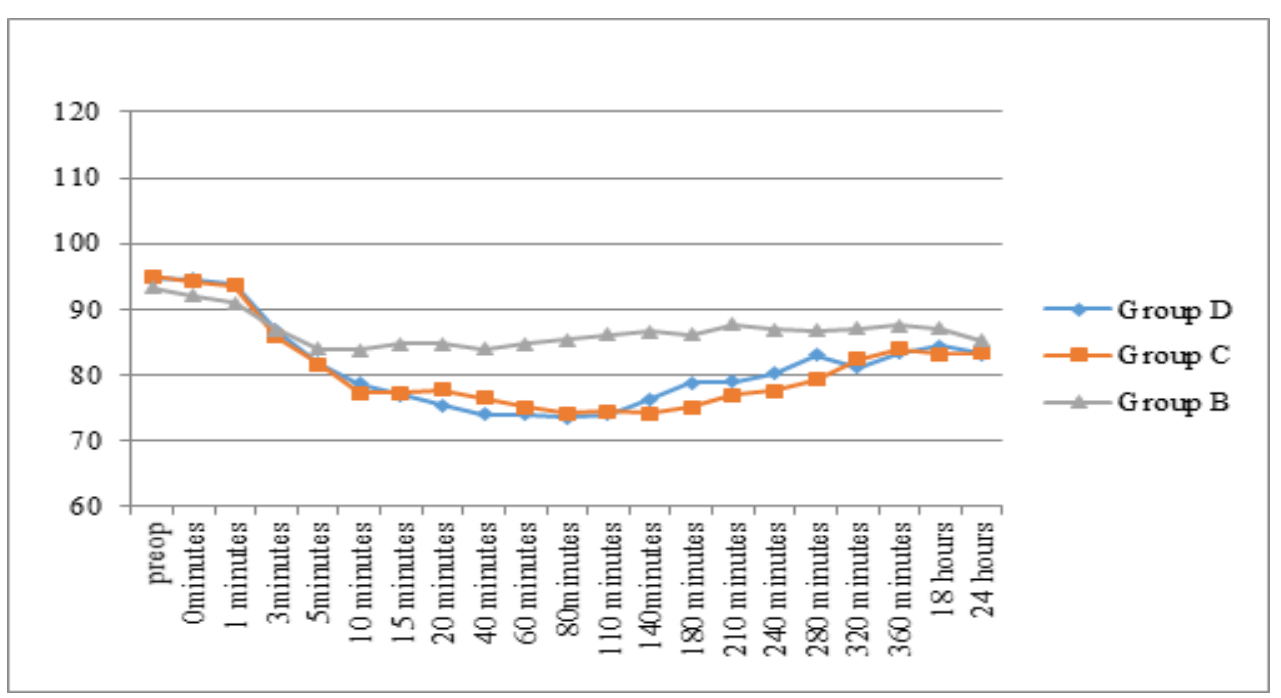

Fig. 1: Mean Pulse Rate

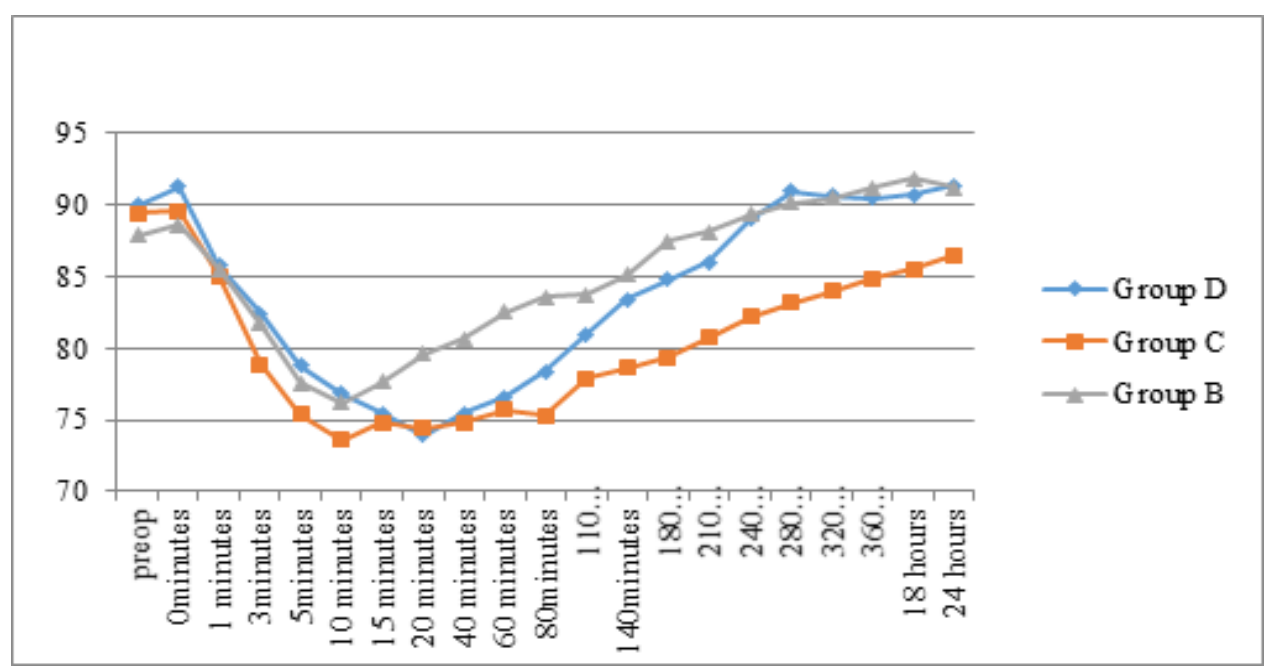

Fig. 2: Mean Arterial Blood Pressure

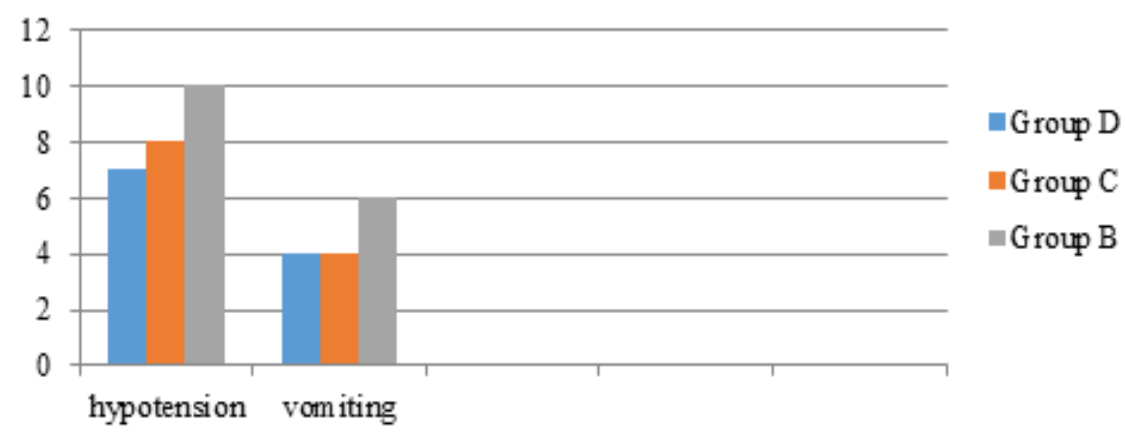

Fig. 3: Complications 


\section{Discussion}

Additives in regional anaesthesia extend the duration of analgesia in post-operative period. ${ }^{3}$ In our study we compared the spinal additive effect of dexmedetomidine and clonidine. Clonidine is used in high dose $(1-2 \mu \mathrm{g} / \mathrm{kg})$ intrathecally to increase the sensory and motor blockade of the local anaesthetics. This high dose clonidine improves analgesia but it is also associated with side effects like sedation, hypotension and bradycardia. ${ }^{7}$ In our study the low dose clonidine $(15 \mu \mathrm{g})$ along with bupivacaine $10 \mathrm{mg}(2 \mathrm{ml})$ improves the onset and duration of sensory and motor blockade. It also increases the first analgesic requirement time with minimal side effects. The sensory blockade of Clonidine is by its vasoconstrictive effect. Van Tuijl et al showed peak sensory level was not dose dependent and the duration of peak sensory level was 4minutes which was similar to our study. ${ }^{8}$

De kock et al also recorded that increasing the dose of clonidine from 15 to $45 \mu \mathrm{g}$ did not increase the duration of sensory and motor blockade. ${ }^{9}$ Intrathecal clonidine potentiates the local anaesthetic action by cellular modification in the ventral horn of the spinal cord and thereby potentiates the motor blockade duration. Dobrydnjov et al compared $15 \mu \mathrm{g}$ and $30 \mu \mathrm{g}$ of clonidine with $6 \mathrm{mg}$ hyperbaric bupivacaine for inguinal hernia repair. ${ }^{10}$ They found that the duration of motor blockade was $155 \mathrm{mins}$ and 185 minutes in $15 \mu \mathrm{g}$ and $30 \mu \mathrm{g}$ of clonidine groups respectively. In our study the motor blockade was (210 minutes) which was similar to that of the previous study.

$\alpha 2$ agonists produce sympatholysis and reduction in arterial blood pressure through direct effect on brain stem nuclei and on preganglionic sympathetic neuron level. Normally this effect is counteracted by the peripheral vasoconstrictive action. The sympatholytic effect was enhanced with local anaesthetics and produces excessive fall in blood pressure. ${ }^{7}$

Dobrydnjov et al observed that increasing the dosage of clonidine caused increasing changes in hemodynamics causing hypotension. ${ }^{10} \mathrm{He}$ also observed that clonidine did not have any direct effect on heart rate. In our study with $15 \mu \mathrm{g}$ clonidine there was no significant hemodynamic complications observed. Only 8 out of 30 patients showed mild to moderate hypotension and there was no incidence of bradycardia. The hypotension was effectively managed with $6 \mathrm{mg}$ of ephedrine. Sethi et al documented that the high dose clonidine was associated significant rise in nausea and vomiting. ${ }^{11}$ But in our study with low dose clonidine, only 4 out of 30 patients had nausea and vomiting.

Central sedative effect is well known with $\alpha 2$ agonist. Nicmi et al and Aaalovschi et al documented that the sedative action is dose dependent.) They observed significant sedation with $1 \mu \mathrm{g} / \mathrm{kg}$ dosage when used intrathecally. In our study the maximum sedation score observed was 2 .
Sethi et al documented dryness of mouth is one of the side effects observed with $1 \mu \mathrm{g} / \mathrm{kg}$ dosage of clonidine. In our study there was no incidence of dryness mouth. ${ }^{11}$

Ranju Singh et al observed that intrathecal clonidine in dosage of $50 \mu \mathrm{g}$ or $75 \mu \mathrm{g}$ did not produce any maternal or neonatal side effects. ${ }^{12}$ Another study done by nikil Kothari et al showed no neonatal side effects with $50 \mu \mathrm{g}$. In our study also there is no maternal and neonatal side effects (Agar score $7.73 \pm 0.45 ; 9.43 \pm 0.50$ )

Dexmedetomidine is a newer selective $\alpha 2$ agonist. The analgesic action is not well known. But it may exert their action through presynaptic $\mathrm{C}$ fibres and post synaptic dorsal horn neurons. It potentiates local anaesthetic action through the same mechanism as that of clonidine.

S.Fyneface-Organ et al, used intrathecal low dose Dxm $(2.5 \mu \mathrm{g})$ with low dose bupivacaine for uncomplicated vaginal delivery as labor analgesic technique. ${ }^{13}$ They observed the extent of analgesia in post delivery period and there were no neonatal or maternal side effects. S.M .Al Ghanem et al found the duration of sensory block with intrathecal Dxm (5 and $10 \mu \mathrm{g}$ Dxm) was dose dependent. In our study intrathecal bupivacaine with Dxm $5 \mu \mathrm{g}$ significantly prolong the post operative analgesic period like the previous study.

In my study both the $\alpha 2$ agonists significantly increase the time for first analgesic requirement (D$231 \pm 17.08$; C-316 \pm 16.93 ). Axelsson and Gupta found that intrathecal $\alpha 2$ agonists improved the quality of post operative analgesia by increasing the duration of 2 segment regression time and motor blockade in a dose dependent manner. ${ }^{14}$ In our study both the $\alpha 2$ agonists increased the 2 segment regression time(D-103.47 \pm 8.08 ; C-108 \pm 6.90 ) and also duration of the motor blockade (D$304 \pm 22.53 ; \mathrm{C}-294.67 \pm 28.73)$ as compared to placebo group $(67.53 \pm 5.94$ and $214 \pm 17.14)$.

The study regarding transfer of clonidine and Dxm across the isolated human placenta showed that the transfer was faster with Dxm than clonidine. ${ }^{15}$ This is because of the increased lipophilicity of Dxm which leads to placental tissue retention of Dxm than clonidine. S.Fyneface-Organ et al observed no significant neonatal depression with Dxm. They used multiple parameters for neonatal assessment. We used Apgar score at 1 st and $5^{\text {th }}$ minute to assess the neonatal wellbeing. There was no significant neonatal depression in both the Dxm and clonidine $(8.07 \pm 0.45 ; 9.27 \pm 0.45)$ compared to the control group $(7.97 \pm 0.18 ; 9.13 \pm 0.35)$. Many studies have shown the safety aspect of Dxm in pediatric population as an intravenous ICU sedation. Shukry et al and Munro et al used Dxm as a sole intravenous anaesthetic agent in pediatric general anaesthesia without any side effects, where it prevented the emergence delirium from GA.

A follow up study was done by Gupta et al to rule out neurological complication following intrathecal Dxm. ${ }^{14}$ In that 4 weeks follow up did not notice any form 
of neurological deficit. They reported that $5 \mu \mathrm{g}$ intrathecal Dxm as compared to intrathecal fentanyl 25 $\mu \mathrm{g}$ produced better post operative analgesia and did not produce any hemodynamic adverse effect. Similarly in our study good post operative analgesia without any significant side effects were observed in Dxm group.

The most significant side effect of intrathecal $\alpha 2$ agonists are hypotension and bradycardia. With reduction in intrathecal dose of $\alpha 2$ agonists unwanted hypotension and bradycardia may be prevented. In our study we observed no bradycardia and minimal hypotension in both Dxm and clonidine groups. They were more with control group with bupivacaine $(10 \mathrm{mg})$.

\section{Conclusion}

Our study shows that addition of intrathecal clonidine $15 \mu \mathrm{g} /$ dexmedetomidine $5 \mu \mathrm{g}$ to $10 \mathrm{mg}$ of bupivacaine in LSCS patients increase the duration of motor and sensory blockade, with little changes in maternal hemodynamics without any changes in neonatal outcome. Both clonidine and dexmedetomidine add adequate sedation during perioperative period and also improve the quality of analgesia in the postoperative period. Comparing dexmedetomidine and clonidine the duration of post-operative analgesia was longer with clonidine.

\section{References}

1. Anita Backus Chang, M.D,

Vijaya Gottumukkala, M.B.B.S., M.D. David

L. Brown, M.D., David H.Chestnut: Obstetric Anesthesia: Principles and Practice, 3rd ed.

2. Alan C. Santos, M.D., M.P.H., and Mieczyslaw Finster, M.D: Obstetric Anaesthesia: Principles and Practice, $3^{\text {rd }}$ Ed.

3. Asokumar Buvanendran MD, Jeffrey S. Kroina PhD, Useful adjuvants for postoperative pain management; Best Practice \& Research Clinical Anaesthesiology Vol. 21, No. 1, pp. 31e49, 2007

4. Etches RC, Sandler AN, Daley MD. Respiratory depression and spinal opioids. Can J Anaesth 1989; 36:165-85.

5. J.G. Reves, Peter S.A. Glass, David A. Lubarsky, Matthew D. McEvoy, Ricardo Martinez-Ruiz, and David L.Brown: Ronald D. Miller $7^{\text {th }}$ ed.

6. Stoelting, Robert K.; Hillier, Simon C. Handbook of Pharmacology and Physiology in Anesthetic Practice, 2nd Edition.

7. Kothari N, Bogra J, Chaudhary AK. Evaluation of analgesic effects of intrathecal clonidine along with bupivacaine in cesarean section. Saudi J Anaesth 2011;5:31-5.

8. Van Tuijl I, van Klei WA, van der Werff DB, Kalkman CJ. The effect of addition of intrathecal clonidine to hyperbaric bupivacaine on postoperative pain and morphine requirements after caesarean section: A randomized controlled trial. Br J Anaesth 2006; 97:36570.

9. Eisenach JC, De Kock M, Klimscha W. Alpha (2)adrenergic agonists for regional anesthesia. A clinical review of clonidine (1984-1995). Anesthesiology 1996;85:655-74.
10. Dobrydnjov I, Axelsson K, Thorn SE, Matthiesen P, Klockhoff H, Olmstrom B, et al. Clonidine combined with small dose bupivacaine during spinal anesthesia for inguinal herniorrhaphy: A randomized double-blinded study. Anesth Analg 2003;96:1496-503.

11. Sethi BS, Samuel M, Sreevastava D. Efficacy of analgesic effects of low dose intrathecal clonidine as adjuvant to bupivacaine. Indian J Anaesth. 2007;51:4159002E.

12. Singh R, Gupta D, Jain A. The effect of addition of intrathecal clonidine to hyperbaric bupivacaine on postoperative pain after lower segment caesarean.

13. Fyneface-Ogan, O. Gogo Job and C. E. Enyindah Comparative Effects of Single Shot Intrathecal Bupivacaine with Dexmedetomidine and Bupivacaine with Fentanyl on Labor Outcome. ISRN Anesthesiology, Volume 2012, Article ID 816984, 6 pages.

14. Ranji Gupta, Reetu Verma,Jaishri Bogra, Monica Kohli, Rajesh Raman, Jitendra Kumar Kushwaha, A comparative study of intrathecal dexmedetomidine and fentanyl as adjuvants to bupivacaine.JAnaesth Clin Pharmacol 2011:27:339-43.

15. Wafiya Ramadan Mahdy, Sabry Ibrahim Abdullah Effect of adding dexmedetomidine versus fentanyl to intrathecal bupivacaine on spinal block characteristic and neonatal outcome in uncomplicated cesarean delivery: A randomized double blind placebo controlled study. Menoufiya Medical Journal, vol 24 No.1Jan 2011:221. 